\title{
Impact of Diabetic Status on the Hyperglycemia-Induced Adverse Risk of Short Term Outcomes in Hospitalized Patients with Acute Coronary Syndromes in the Middle East: Findings from the Gulf Registry of Acute Coronary Events (Gulf RACE)
}

Lukman Thalib, PhD; Mohammad Zubaid, FRCPC; Wafa Rashed, FRCP (Lond); Jassim Al Suwaidi, FACC; Wael Almahmeed, FRCPC; Ebaa Alozairi, MRCP; Muath Alanbaei, FRCPC; Kadhim Sulaiman, FRCPI; Haitham Amin, FRCPC; and Ahmed Al-Motarreb, PhD

Background: While glucose levels on admission are clearly a much stronger predictor of short term adverse outcomes than diabetes status, there is a paucity of data on how diabetes status impacts the hyperglycemia-induced increased risk.

Methods: 2786 patients admitted to the hospital with acute coronary syndrome (ACS) and diabetic level hyperglycemia (random $>11.1 \mathrm{mmol} / \mathrm{L}$ or fasting $>7 \mathrm{mmol} / \mathrm{L}$ ) were identified from a Gulf registry of ACS. We divided the cohort into two groups. Those who were previously known to have diabetes mellitus were identified as the known diabetes group, and the non-diabetic group included those without a previous diabetes diagnosis. We used logistic regression models to assess the effect of glycemic status on hospital mortality and other patient outcomes including heart failure, stroke, recurrent ischemia, cardiogenic shock, major bleeding, and ventilation.

Results: About two-thirds of the hyperglycemics on admission had been diagnosed previously with diabetes. After adjusting for age, in-hospital mortality was significantly higher in the non-diabetic group (OR: 2.36; 95\% Cl I.54-3.6I) compared to the diabetic group. As for the other outcomes, known diabetes patients had significantly lower incidences of heart failure, cardiogenic shock, and ventilation compared to non-diabetic patients.

Conclusion: The effects of hyperglycemia are mitigated by the presence of the chronic diabetic state, and thus, hyperglycemia has a worse effect in those not known to have chronic diabetes. These findings are important and call for further investigation.

Keywords: Acute coronary syndrome; Adverse events; Diabetes; Hyperglycemia

Corresponding Author: Dr. Lukman Thalib, Associate Professor: Department of Community Medicine (Biostatistics); Faculty of Medicine; PO Box 24923; Safat I3II0, Kuwait; Tel: +965-2498 6779; Fax: +965- 25334968; E-mail: Ithalib@hsc.edu.kw
Received: June 13,2010

Revised: August 27, 2010

Accepted: September 13,2010

doi: $10.3121 / \mathrm{cmr} .2010 .946$

Disclosure: Gulf RACE is a Gulf Heart Association project and was financially supported by Sanofi Aventis and Qatar Telecommunications Company. The sponsors had no role in study design, data collection or data analysis, nor did they have a role in the writing of the report and submission of the manuscript. 
$\mathrm{S}$

everal studies over the last decade have linked hyperglycemia at the time of hospital admission with subsequent higher mortality in patients with acute coronary syndrome (ACS), including acute myocardial infarction (AMI) ${ }^{1-7}$ There is also some evidence linking hyperglycemia with increased incidence of stroke and other complications. ${ }^{8}$ The effect of admission hyperglycemia on mortality seems to be independent of a previous diagnosis of diabetes mellitus; indeed, some studies suggest that mortality may be higher in patients with hyperglycemia who are not known to have diabetes compared to those with a known history of diabetes. ${ }^{9}$ Recent regional registries have documented the presence of high rates of diabetes and hyperglycemia among our ACS populations. ${ }^{10-13}$ While it is now clear that hyperglycemia poses a risk independent of diabetes status, what we do not know is whether a diabetic versus a non-diabetic, given the same degree of hyperglycemia, have different risk profiles. A recent study demonstrated that diabetes history alone predicted 30 -day death (OR 1.63, 95\% CI 1.48-1.78, $P<0.0001$ ), but not after adjusting for average glucose (OR $0.98,95 \%$ CI 0.88 -
$1.09, P=0.72) .{ }^{14}$ So, while glucose levels are clearly a much stronger predictor of death than diabetes status, they were unable to inform on how diabetes impacts on the hyperglycemiainduced increased risk. We therefore analyzed data from the recently conducted Middle Eastern ACS registry (Gulf Registry of Acute Coronary Events [Gulf RACE]), to evaluate the influence of diabetes, independent of hyperglycemia, on hospital mortality and other major patient outcomes.

\section{Methods}

Gulf RACE was a prospective, multinational, multicenter, observational study of patients hospitalized with the final diagnosis of ACS in six Middle Eastern countries in the Gulf region. Full details of the methods have been published previously. ${ }^{15-16}$ Consecutive patients were recruited over a sixmonth period from 64 hospitals in six Middle Eastern countries. The participating countries were Bahrain, Kuwait, Qatar, Oman, United Arab Emirates (UAE), and Yemen. In Bahrain, Kuwait, and Qatar, all hospitals nationwide that admit patients with ACS participated in the survey. In Oman, UAE, and Yemen, most hospitals (covering at least $85 \%$ of the

Table 1. Socio-demographic characteristics, baseline data, past history and final diagnosis $(n=2786)$.

\begin{tabular}{|c|c|c|c|}
\hline & \multicolumn{2}{|c|}{ Diabetic-level hyperglycemia } & \multirow[b]{2}{*}{$P$ value } \\
\hline & $\begin{array}{l}\text { Diabetes } \\
(n=1889)\end{array}$ & $\begin{array}{l}\text { No diabetes } \\
\qquad(n=897)\end{array}$ & \\
\hline Age, mean (SD) & $58.5(11.5)$ & $56.1(12.9)$ & $<0.001$ \\
\hline First glucose (random), mean (SD) & $12.8(3.9)$ & $10.1(3.7)$ & $<0.001$ \\
\hline Fasting glucose, mean (SD) & $9.8(3.2)$ & $8.3(2.3)$ & $<0.001$ \\
\hline BMI, mean (SD) & $28.6(5.7)$ & $27.2(5.2)$ & $<0.001$ \\
\hline Gender, n (\%) & & & $<0.001$ \\
\hline Male & $1272(67.3)$ & $724(80.9)$ & \\
\hline Female & $617(32.7)$ & $171(19.1)$ & \\
\hline Aspirin use, $\mathrm{n}(\%)$ & $1030(54.5)$ & $265(29.5)$ & $<0.001$ \\
\hline Current smokers, n (\%) & $540(28.6)$ & $352(39.2)$ & $<0.001$ \\
\hline Killip Class*, n (\%) & & & 0.005 \\
\hline I & $1388(73.7)$ & $672(75.2)$ & \\
\hline II & $310(16.5)$ & $122(13.6)$ & \\
\hline III & $157(8.3)$ & $70(7.8)$ & \\
\hline IV & $29(1.5)$ & $30(3.4)$ & \\
\hline \multicolumn{4}{|l|}{ Past history, n (\%) } \\
\hline Angina & $933(49.4)$ & $282(31.4)$ & $<0.001$ \\
\hline MI & $595(31.5)$ & $151(16.8)$ & $<0.001$ \\
\hline $\mathrm{PCl}$ & 289 (15.3) & $70(7.8)$ & $<0.001$ \\
\hline CABG & $171(9.1)$ & $24(2.7)$ & $<0.001$ \\
\hline Hypertension & 1275 (67.5) & $323(36)$ & $<0.001$ \\
\hline Hyperlipidemia & $860(45.5)$ & $182(20.3)$ & $<0.001$ \\
\hline Final diagnosis & & & $<0.001$ \\
\hline STEMI & 564 (29.9) & $489(54.5)$ & \\
\hline NSTEMI & 737 (39) & $236(26.3)$ & \\
\hline LBBB MI & 25 (1.3) & $14(1.6)$ & \\
\hline Unstable angina & $563(29.8)$ & $158(17.6)$ & \\
\hline
\end{tabular}

*The Killip classification is a system used in individuals with an acute myocardial infarction, in order to risk stratify them. Individuals with a low Killip class are less likely to have short term adverse events than those with high Killip class. BMI = Body mass index; $\mathrm{Ml}=\mathrm{myocardial}$ infarction; $\mathrm{PCl}=\mathrm{percutaneous}$ coronary intervention; CABG = coronary artery bypass graft; STEMI = ST elevation myocardial infarction; NSTEMI = non-ST elevation myocardial infarction; LBBB MI = left bundle branch block myocardial infarction. 
Table 2. Crude and adjusted odds ratios and $95 \%$ confidence intervals obtained using logistic regression models to quantify the variability of hospital mortality in association with diabetic status $(n=2786)$.

\begin{tabular}{lll}
\hline & \multicolumn{2}{c}{ Diabetic-level hyperglycemia } \\
\cline { 2 - 3 } Mortality type & $\begin{array}{l}\text { Diabetes } \\
(\mathbf{n}=\mathbf{1 8 8 9})\end{array}$ & \multicolumn{1}{c}{$\begin{array}{l}\text { No Diabetes } \\
(\mathbf{n}=\mathbf{8 9 7})\end{array}$} \\
\hline In-hospital & & \\
$\quad$ Mortality Freq (\%) & $47(2.5)$ & $44(4.9)$ \\
$\quad$ OR (95\% Cl) & 1.00 & $2.02(1.33-3.07)$ \\
$\quad P$ value & & 0.001 \\
Age-Adjusted & 1.00 & $2.36(1.54-3.61)$ \\
$\quad$ OR (95\% Cl) & & $<0.001$ \\
$\quad P$ value & 1.00 & $2.38(1.55-3.66)$ \\
Age and gender-adjusted $\quad$ & $<0.001$ \\
$\quad$ OR (95\% Cl) & & $1.89(1.21-2.95)$ \\
$\quad P$ value & 1.00 & 0.005 \\
Age, gender and final diagnosis-adjusted & & \\
$\quad$ OR (95\% Cl) & & \\
$\quad P$ value & &
\end{tabular}

population) participated in the survey. Recruitment in the pilot phase started on May 8, 2006 and lasted for 30 days. Enrollment in the next phase of the registry started on January 29, 2007 and continued for five months. We report on the entire six months of the registry. Diagnosis of the different types of ACS and definitions of data variables were based on the American College of Cardiology (ACC) clinical data standards. ${ }^{17}$

\section{Ethics}

The study received ethical approval from the institutional ethical bodies in all participating countries. A consent form was not required by the ethical committees of the participating countries as this was an observational study. At no stage were patients identified to anyone other than the treating physician. No intervention or out-of-hospital follow-up was carried out. All management decisions were left to the discretion of the treating physician.

\section{Glycemic Status}

We followed the recommendations of the American Diabetes Association (ADA) to classify our patients according to their glycemic status. ${ }^{18}$ Patients were divided into two groups: those admitted with a known history of diabetes formed the diabetes group, and those without a known history of diabetes comprised the non-diabetic group. Patients in both groups were included only if their first fasting glucose after admission was greater than $7 \mathrm{mmol} / \mathrm{L}$, and/or a random glucose on admission was greater than $11.1 \mathrm{mmol} / \mathrm{L}$. Patients who were not hyperglycemic on admission or on a subsequent fasting glucose were excluded from the analysis.

\section{Statistical Analysis}

We evaluated the predictive value of various glycemic statuses on subsequent in-hospital mortality, recurrent ischemia, heart failure, cardiogenic shock, stroke, ventilation, and major bleeding during the course of hospitalization using bivariate logistic regression models. In addition, multivariate models were used to assess the predictive values of glycemic status on patient outcomes after adjusting for age and gender. We reported the adjusted odds ratios (OR) along with $P$ values and $95 \%$ confidence interval $(\mathrm{CI})$ from the bivariate and multivariate models.

\section{Results}

A total of 8,173 ACS patients were included in the Gulf RACE registry. Of these, 2,786 were hyperglycemic by our criteria, with $68 \%$ in the known diabetes group and $32 \%$ in the non-diabetic group. The mean age was 57 years with a standard deviation of 12 years. Approximately $72 \%$ of patients were male.

Many baseline characteristics were different among the two groups (table 1). Patients with known diabetes were more often female and had a higher prevalence of previous coronary artery disease, hypertension, and hyperlipidemia. In-hospital mortality among patients without known diabetes $(4.9 \%$; OR: 2.02) was significantly higher than among patients with diabetes (2.5\%). Even after adjusting for age, gender, and final diagnosis this difference remained statistically significant (adjusted OR: 1.89) (table 2).

Table 3 summarizes the effects of glycemic status on other short-term patient outcomes. The incidence of recurrent ischemia and stroke was not significantly different in patients admitted with known diabetes than those without. Heart failure, ventilation, and cardiogenic shock were, however, significantly increased in patients admitted without known diabetes.

\section{Discussion}

This study shows that given the same degree of hyperglycemia on admission, known diabetes has a protective influence on short-term outcomes in hospitalized ACS patients. In-hospital mortality, perhaps being the major concern to ACS patients, is known to be significantly increased by hyperglycemia, and 
Table 3. Crude and adjusted odds ratios and $95 \%$ confidence intervals obtained using logistic regression models to quantify the in hospital patients outcome in acute coronary syndrome patients with diabetic status $(n=2786)$.

\begin{tabular}{|c|c|c|}
\hline \multirow[b]{2}{*}{ Patient outcomes } & \multicolumn{2}{|c|}{ Diabetic-level hyperglycemia } \\
\hline & $\begin{array}{l}\text { Diabetes } \\
(n=1889)\end{array}$ & $\begin{array}{c}\text { No Diabetes } \\
(n=897)\end{array}$ \\
\hline \multicolumn{3}{|l|}{ Recurrent ischemia } \\
\hline $\mathrm{n}(\%)$ & $200(10.6)$ & 89 (9.9) \\
\hline Crude OR (95\%Cl) & 1.00 & $0.93(0.72-1.2)$ \\
\hline Age adjusted & 1.00 & $0.94(0.72-1.2)$ \\
\hline Age and gender adjusted & 1.00 & $0.96(0.73-1.25)$ \\
\hline \multicolumn{3}{|l|}{ Heart Failure } \\
\hline n (\%) & $356(18.9)$ & $200(22.3)$ \\
\hline Crude OR (95\%Cl) & 1.00 & $1.24(1.02-1.5)$ \\
\hline Age adjusted & 1.00 & $1.38(1.13-1.68)$ \\
\hline Age and gender adjusted & 1.00 & $1.39(1.13-1.7)$ \\
\hline \multicolumn{3}{|l|}{ Ventilation } \\
\hline $\mathrm{n}(\%)$ & $74(3.9)$ & $70(7.8)$ \\
\hline Crude OR $(95 \% \mathrm{Cl})$ & 1.00 & $2.08(1.48-2.91)$ \\
\hline Age adjusted & 1.00 & $2.31(1.64-3.25)$ \\
\hline Age and gender adjusted & 1.00 & $2.35(1.67-3.33)$ \\
\hline \multicolumn{3}{|l|}{ Cardiogenic Shock } \\
\hline n (\%) & $82(4.3)$ & $73(8.2)$ \\
\hline Crude OR $(95 \% \mathrm{Cl})$ & 1.00 & $1.95(1.41-2.71)$ \\
\hline Age adjusted & 1.00 & $2.1(1.51-2.92)$ \\
\hline Age and gender adjusted & 1.00 & $2.14(1.53-2.98)$ \\
\hline \multicolumn{3}{|l|}{ Stroke } \\
\hline $\mathrm{n}(\%)$ & $8(0.4)$ & $7(0.8)$ \\
\hline Crude OR $(95 \% \mathrm{Cl})$ & 1.00 & $1.85(0.67-5.12)$ \\
\hline Age adjusted & 1.00 & $2.07(0.75-5.75)$ \\
\hline Age and gender adjusted & 1.00 & $1.99(0.71-5.61)$ \\
\hline \multicolumn{3}{|l|}{ Major bleeding } \\
\hline n (\%) & $15(0.8)$ & $14(1.6)$ \\
\hline Crude OR $(95 \% \mathrm{Cl})$ & 1.00 & $1.98(0.95-4.13)$ \\
\hline Age adjusted & 1.00 & $2.17(1.04-4.54)$ \\
\hline Age and gender adjusted & 1.00 & $2.03(0.96-4.27)$ \\
\hline
\end{tabular}

we have demonstrated that this effect is less in known diabetes. Also, known diabetes protects against the deleterious effects of hyperglycemia on other short-term outcomes in varying degrees.

While it is clear that there is an increased mortality in ACS patients with hyperglycemia on admission, ${ }^{15-18}$ our findings expand on current knowledge by demonstrating that the known diabetic state mitigates both the mortality and other major adverse patient outcomes associated with elevated blood glucose levels on admission.

It is thought that hyperglycemia exerts toxic effects, possibly through the generation of oxidative stress. ${ }^{19}$ These effects may be less in those with long-standing diabetes and may explain why reports on the influence of known diabetes on mortality are conflicting. Nordin et $\mathrm{al}^{20}$ showed that diabetes influence on mortality loses significance after adjusting for variables such as age, and a recent study on myocardial infarction patients in Qatar with a large sample size of 1,598 , that has sufficient power, failed to find a significant relationship between diabetes and in-hospital mortality. ${ }^{21}$ On the other hand, Stranders et $\mathrm{al}^{6}$ report that pre-existing diabetes increases the short- and long-term mortality after myocardial infarction. Proponents of diabetes leading to a worse outcomes usually argue that diabetic patients are expected to have a worse ventricular function compared to patients without diabetes, which limits the ability of the non-infarcted myocardium to compensate, or that diabetics have a worse risk profile. ${ }^{22-24} \mathrm{We}$ did find that patients with known diabetes have a worse risk profile and increased mortality, but this did not seem to impact on its protective effect against hyperglycemia. Some of the studies that showed pre-existing diabetes to be a more important influence on mortality compared to admission hyperglycemia, may have suffered from having not fully adjusted for important confounders like hyperglycemia in the way we have done. ${ }^{22}$

There is a paucity of data on the effect of diabetes (separate from hyperglycemia) on other short-term outcomes such as recurrent ischemia, heart failure, stroke, bleeding, and cardiogenic shock. Few recent studies have noted that cardiogenic shock ${ }^{25}$ and heart failure ${ }^{26}$ in ACS patients could be predicted by pre-existing diabetes status. Our findings 
show that cardiogenic shock, ventilation, and heart failure are predicted by elevated blood glucose on admission, and that diabetes protects against such an occurrence. Again, other reports are confounded by the interplay between the worse effects of hyperglycemia and the protective effects of diabetes, and the inability to extricate one from the other.

The findings of this study should be evaluated in light of its strengths and limitations. We used the largest registry of ACS population in the Middle East to assess the relationship between diabetes, mortality and other outcomes, while controlling for glycemic status. Statistical power in our study is, therefore, expected to be high. Our findings have important clinical implications given the high prevalence of diabetes and hyperglycemia on admission, which accounted for about $70 \%$ in our ACS patients. In addition, our ACS patients were exceptionally younger in age than most other ACS registries, with a mean age of only 57 years.

In conclusion, known diabetes and hyperglycemia on admission adversely influence outcome in patients hospitalized with ACS. However, if they are compared to a baseline population without diabetes who are normoglycemic, ${ }^{14}$ we have shown that, when both diabetes and hypergylcemia are present, there is an interaction, and these effects of hyperglycemia are mitigated by the presence of the chronic diabetic state. Further investigation is necessary to confirm these important findings.

\section{References}

1. Petursson P, Herlitz J, Caidahl K, Gudbjornsdottir S, Karlsson T, Perers E, Sjöland H, Hartford M. Admission glycaemia and outcome after acute coronary syndrome. Int J Cardiol 2007;116:315-320.

2. Milvidaite I, Slapikas R, Statkeviciene A, Babarskiene MR, Luksiene D, Slapikiene B. [Admission hyperglycemia and abnormal glucose tolerance at discharge in patients with acute myocardial infarction and no previous history of diabetes mellitus]. [Article in Lithuanian] Medicina (Kaunas) 2007;43:935-941.

3. Schiele F, Descotes-Genon V, Seronde MF, Blonde MC, Legalery P, Meneveau N, Ecarnot F, Mercier M, Penfornis A, Thebault L, Boumal D, Bassand JP; Investigators of the Réseau Franc Comtois de Cardiologie. Predictive value of admission hyperglycaemia on mortality in patients with acute myocardial infarction. Diabet Med 2006;23:1370-1376.

4. Ainla T, Baburin A, Teesalu R, Rahu M. The association between hyperglycaemia on admission and 180-day mortality in acute myocardial infarction patients with and without diabetes. Diabet Med 2005;22:1321-1325.

5. Kosiborod M, Rathore SS, Inzucchi SE, Masoudi FA, Wang Y, Havranek EP, Krumholz HM. Admission glucose and mortality in elderly patients hospitalized with acute myocardial infarction: implications for patients with and without recognized diabetes. Circulation 2005;111:30783086.

6. Stranders I, Diamant M, van Gelder RE, Spruijt HJ, Twisk JW, Heine RJ, Visser FC. Admission blood glucose level as risk indicator of death after myocardial infarction in patients with and without diabetes mellitus. Arch Intern Med 2004;164:982-988.
7. Angeli F, Verdecchia P, Karthikeyan G, Mazzotta G, Del Pinto M, Repaci S, Gatteschi C, Gentile G, Cavallini C, Reboldi G. New-onset hyperglycemia and acute coronary syndrome: a systematic overview and meta-analysis. Curr Diabetes Rev 2010;6:102-110.

8. Poppe AY, Majumdar SR, Jeerakathil T, Ghali W, Buchan AM, Hill MD; Canadian Alteplase for Stroke Effectiveness Study Investigators. Admission hyperglycemia predicts a worse outcome in stroke patients treated with intravenous thrombolysis. Diabetes Care 2009;32:617-622.

9. Kolman L, Hu YC, Montgomery DG, Gordon K, Eagle KA, Jackson EA. Prognostic value of admission fasting glucose levels in patients with acute coronary syndrome. Am J Cardiol 2009; 104:470-474.

10. AlHabib KF, Hersi A, AlFaleh H, Kurdi M, Arafah M, Youssef M, AlNemer K, Bakheet A, AlQarni A, Soomro T, Taraben A, Malik A, Ahmed WH. The Saudi Project for Assessment of Coronary Events (SPACE) registry: design and results of a phase I pilot study. Can J Cardiol 2009;25:e255-e258.

11. Zubaid M, Rashed WA, Al-Khaja N, Almahmeed W, Al-Lawati J, Sulaiman K, Al-Motarreb A, Amin H, Al-Suwaidi J, Al-Habib K. Clinical presentation and outcomes of acute coronary syndromes in the gulf registry of acute coronary events (Gulf RACE). Saudi Med J 2008;29:251-255.

12. Zubaid M, Rashed WA, Saad H, Attiya A, Al-Banat BA, Ridha M, Al-Kandari MH, Baidas G, Al-Hamdan R, Zubair S, Thalib L. Kuwait acute coronary syndromes registry: baseline characteristics, management practices and in-hospital outcomes of patients hospitalized with acute coronary syndromes in Kuwait. Med Princ Pract 2007; 16:407-412.

13. Zubaid M, Rashed WA, Husain M, Mohammad BA, Ridha M, Basharuthulla M, Rezq MA, Smid J, Thalib L. A registry of acute myocardial infarction in Kuwait: Patient characteristics and practice patterns. Can J Cardiol 2004;20:783-787.

14. Goyal A, Mehta SR, Gerstein HC, Diaz R, Afzal R, Xavier D, Zhu J, Pais P, Lisheng L, Kazmi KA, Zubaid M, Piegas LS, Widimsky P, Budaj A, Avezum A, Yusuf S. Glucose levels compared with diabetes history in the risk assessment of patients with acute myocardial infarction. Am Heart J 2009; 157:763-770.

15. Foo K, Cooper J, Deaner A, Knight C, Suliman A, Ranjadayalan K, Timmis AD. A single serum glucose measurement predicts adverse outcomes across the whole range of acute coronary syndromes. Heart 2003;89:512-516.

16. Monteiro S, Monteiro P, Gonçalves F, Freitas M, Providência LA. Hyperglycaemia at admission in acute coronary syndrome patients: prognostic value in diabetics and nondiabetics. Eur J Cardiovasc Prev Rehabil 2010;17:155-159.

17. Wahab NN, Cowden EA, Pearce NJ, Gardner MJ, Merry H, Cox JL; ICONS Investigators. Is blood glucose an independent predictor of mortality in acute myocardial infarction in the thrombolytic era? J Am Coll Cardiol 2002;40:1748-1754.

18. Capes SE, Hunt D, Malmberg K, Gerstein HC. Stress hyperglycaemia and increased risk of death after myocardial infarction in patients with and without diabetes: a systematic overview. Lancet 2000;355:773-778.

19. Ceriello A. Cardiovascular effects of acute hyperglycaemia: pathophysiological underpinnings. Diab Vasc Dis Res 2008;5:260-268.

20. Nordin C, Amiruddin R, Rucker L, Choi J, Kohli A, Marantz PR. Diabetes and stress hyperglycemia associated with myocardial infarctions at an urban municipal hospital: prevalence and effect on mortality. Cardiol Rev 2005; 3:223-330. 
21. El-Menyar AA, Albinali HA, Bener A, Mohammed I, Al Suwaidi J. Prevalence and impact of diabetes mellitus in patients with acute myocardial infarction: a 10-year experience. Angiology 2009-2010;60:683-688.

22. Tang EW, Wong CK, Herbison P. Global Registry of Acute Coronary Events (GRACE) hospital discharge risk score accurately predicts long-term mortality post acute coronary syndrome. Am Heart J 2007;153:29-35.

23. Aronson D, Rayfield EJ, Chesebro JH. Mechanisms determining course and outcome of diabetic patients who have had acute myocardial infarction. Ann Intern Med 1997; 126:296-306.

24. Marso SP, Gowda M, O'Keefe JH, Coen MM, McCallister BD, Giorgi LV, Huber KC, Laster SB, Johnson WL, Rutherford BD. Improving in-hospital mortality in the setting of an increasing risk profile among patients undergoing catheterbased reperfusion for an acute myocardial infarction without cardiogenic shock. J Invasive Cardiol 2003;15:711-716.

25. Dziewierz A, Siudak Z, Rakowski T, Dubiel JS, Dudek D. Predictors and in-hospital outcomes of cardiogenic shock on admission in patients with acute coronary syndromes admitted to hospitals without on-site invasive facilities. Acute Card Care 2010;12:3-9.

26. Saejueng B, Yipintsoi T, Chaisuksuwan R, Kehasukcharoen W, Boonsom W, Kanjanavanit R. Factors related to in-hospital heart failure are very different for unstable angina and nonST elevation myocardial infarction. Heart Vessels 2009;24:399-405.

\section{Author Affiliations}

Lukman Thalib, PhD*; Mohammad Zubaid, FRCPC';

Wafa Rashed, FRCP (Lond); Jassim Al Suwaidi, FACC\$;

Wael Almahmeed, FRCPC"/; Ebaa Alozairi, MRCP广;

Muath Alanbaei, FRCPC广; Kadhim Sulaiman, FRCPI\#,

Haitham Amin, FRCPC ${ }^{* *}$; Ahmed Al-Motarreb, PhD t†

*Department of Community Medicine (Biostatistics), Faculty of Medicine, Kuwait University, Kuwait

tDepartment of Medicine, Faculty of Medicine,

Kuwait University, Kuwait

$\$$ Department of Medicine, Mubarak Al-Kabeer Hospital, Ministry of Health, Kuwait

$\S$ Hamad General Hospital and Hamad Medical

Corporation, Doha, Qatar

"Sheikh Khalifa Medical City, Abu Dhabi,

United Arab Emirates

\#Royal Hospital, Muscat, Oman

**Haitham Amin, Mohammed Bin Khalifa Cardiac Centre, Manama, Bahrain

t'Department of Medicine, Faculty of Medicine,

Sana'a University, Yemen 